\title{
ISLAM DAN BUDAYA MASYARAKAT YOGYAKARTA DITINJAU DARI PERSPEKTIF SEJARAH
}

\author{
Aulia Arif Rahman, IAIN Syekh Nurjati Cirebon, arief aura81@yahoo.com, \\ 081392852626. Khoirul Hodayah, Fakultas Syariah UIN Maliki Malang
}

\begin{abstract}
Abstraks
Yogyakarta merupakan salah satu daerah Istimewa di Indonesia yang mempunyai budaya bernafaskan Islam. Sejarah Kerajaan Mataram sebagai Kerajaan Islam, melalui pejanjian Giyanti (1755) telah melahirkan Keraton Yogyakarta sebagai bagian sejarah Islam di Mataram. Pengaruh Islam dalam masyarakat Yogyakarta dapat dijelaskan melalui teori budaya. Budaya jika ditinjau dari struktur dan tingkatannya dapat dijelaskan bahwa Islam sebagai subculture yang tidak bertentangan dengan culture Jawa sebagai kebudayaan induk, menjadikan Islam dapat diterima masyarakat Jogyakarta sebagai agama yang benar. Nilai-nilai Islam telah menyatu dengan nilai-nilai kehidupan masyarakat Yogyakarta, sehingga banyak cara berpikir dan tindakan yang dilakukan cenderung bernafaskan Islam. Hal ini dapat ditunjukkan melalui seni, sastra, kegiatan sosial dan prinsip hidup yang diyakini masyarakat Jogyakarta.
\end{abstract}

Kata Kunci: Yogyakarta, Mataram, Kultur Islam .

\section{Abstract}

Yogyakarta is one of the Indonesia's special districts embraced the Islamic culture. The history of Mataram Kingdom as the Islamic Kingdom, through Giyanti agreement (1755) gave birth to Yogyakarta Palace as a part of the Islamic history in Mataram. The influence of Islam in its society can be explained by cultural theory. Culture seen from its structure and level could explain that Islam, as a subculture, is not against the Java culture as the main culture, making Islam could be accepted by the Yogyakarta society as the true religion. Islamic values have been fused with the life of Yogyakarta society so that there are many ways of thinking and actions that tend to embrace Islam. This can be shown through art, literature, social activities and the life principles believed by the Yogyakarta society.

Keywords: Yogyakarta, Mataram, Islamic Culture.

\section{Pendahuluan}

Yogyakarta merupakan salah satu propinsi "istimewa" di negara Indonesia. Secara geopolitis, keistimewaan Yogyakarta dipengaruhi oleh letak 
strategis Yogyakarta sebagai pusat kebudayaan Jawa (Yayasan Obor Indonesia, 1999: 89-90). Wacana kesejarahan Propinsi DIY, bermula dari Amanat Sri Sultan Hamengkubuwana IX dan Sri Pakualam VIII, sebagai Raja Keraton Ngayogyakarta Hadiningrat (selanjutnya disebut: Keraton Yogya) dan Kawedanan Pakualaman saat itu, tanggal 5 September 1945, yang menyatakan bergabung dan mendukung Republik Indonesia. Sebagai penghormatan atas sikap tersebut, Presiden Soekarno mengukuhkan Yogyakarta menjadi Propinsi "Daerah Istimewa” dengan Sri Sultan Hamengkubuwana IX dan Sri Pakualam VIII sebagai Kepala Daerah dan wakilnya, dalam piagam pengukuhan dari Presiden Soekarno, serta diperkuat dalam UU No.3 tahun 1950 jo UU No. 19 tahun 1950.

Sejak masa awal berdirinya, Kerajaan Ngayogyakarta Hadiningrat merupakan Kerajaan Islam. Hal ini jelas tercantum dalam dari gelar yang disandang Raja, juga dari simbol-simbol yang dicantumkan dalam bangunan fisik maupun karya sastranya, serta upacara-upacara budaya yang bernafaskan Islam seperti sekaten dan grebek mulud.

Budaya masyarakat yang bernafaskan Islam di Yogyakarta adalah berkaitan dengan sejarah keraton Yogya yang dapat ditelusuri dari adanya perjanjian Giyanti, 13 Februari 1755, yang memunculkan Kerajaan Ngayogyakarta sebagai pewaris Kerajaan Mataram Islam. Berikut ini akan diuraikan pengaruh Islam terhadap budaya masyarakat Yogyakarta dilihat dari perspektif sejarah.

\section{Kajian Budaya}

Kajian disiplin ilmu mendefinisikan istilah budaya (culture) yang dimasukkan ke dalam konsep masing-masing disiplin humaniora dan sosial, seperti antropologi, sosiologi, politik, ekonomi dan seterusnya. Koentjaraningrat memberikan definisi budaya sebagai sistem gagasan, tindakan dan hasil karya manusia dalam rangka kehidupan masyarakat yang dijadikan milik diri manusia dengan belajar (Koentjaraningrat, 1990: 180). Dan, James Spradley nampaknya hampir sependapat dengan Koentjaraningrat. Ia mengatakan budaya merupakan sistem pengetahuan yang diperoleh manusia melalui proses belajar, yang 
kemudian mereka gunakan untuk menginterpretasikan dunia sekelilingnya, sekaligus untuk menyusun strategi perilaku dalam menghadapi dunia sekitar.

Lebih khusus, dalam terminologi disiplin Kajian Budaya (Cultural Studies) menyajikan bentuk kritis atas definisi budaya yang mengarah pada "the complex everyday world we all encounter and through which all move" (Edgar, 1999: 102). Budaya secara luas adalah proses kehidupan sehari-hari manusia dalam skala umum, mulai dari tindakan hingga cara berpiKir, sebagaimana konsep budaya yang dijabarkan oleh Kluckhohn. Pengertian ini didukung juga oleh Clifford Geertz, kebudayaan didefinisikan serangkaian aturan-aturan, resepresep, rencana-rencana dan petunjuk-petunjuk yang digunakan manusia untuk mengatur tingkah lakunya.

Dalam kajian budaya atau Cultural Studies (CS), konsep budaya dapat dipahami seiring dengan perubahan perilaku dan struktur masyarakat di Eropa pada abad ke-19. Perubahan ini atas dampak dari pengaruh teknologi yang berkembang pesat. Istilah budaya sendiri merupakan kajian komprehensif dalam pengertiannya menganalisa suatu obyek kajian. Contohnya, selain ada antropologi budaya juga dikaji dalam studi Sosiologi, Sejarah, Etnografi, Kritik Sastra bahkan juga Sosiobiologi.

Fokus studi kajian budaya (culture centre) ini adalah pada aspek relasi budaya dan kekuasaan yang dapat dilihat dalam budaya pop. Di dalam tradisi Kajian Budaya di Inggris yang diwarisi oleh Raymonds Williams, Hoggarts, dan Stuart Hall, menilai konsep budaya atau "culture” (dalam bahasa Inggris) merpakan hal yang paling rumit diartikan sehingga bagi mereka konsep tersebut disebut sebuah alat bantu yang kurang lebih memiliKi nilai guna.

Williams mendefinisikan konsep budaya menggunakan pendekatan universal, yaitu konsep budaya mengacu pada makna-makna bersama. Makna ini terpusat pada makna sehari-hari: nilai, benda-benda material/simbolis, norma. Kebudayaan adalah pengalaman dalam hidup sehari-hari: berbagai teks, praktik, dan makna semua orang dalam menjalani hidup mereka (Barker, 2005: 50-55). Kebudayaan yang didefinisikan oleh Williams lebih dekat 'budaya' sebagai keseluruhan cara hidup. 


\section{Sejarah Kerajaan Mataram Islam}

Menurut (Hariwijaya, 2007) Budaya masyarakat Yogjakarta yang sudah terbentuk dengan tradisi Islamnya adalah tidak terlepas dari sejarah masuknya Islam di tanah Jawa yang diawali dari sejarah kerajaan Mataram sebagai kerajaan Islam kedua setelah Demak di tanah Jawa. Kerajaan Mataram berdiri pada tahun 1582. pusat kerajaan ini terletak di sebelah tenggara kota Yogyakarta, yakni di Kotagede. Para raja yang pernah memerintah di Kerajaan Mataram yaitu penembahan Senopati (1584-1601), panembahan Seda Krapyak (1601-1677).

Kesultanan Mataram memiliki peran yang cukup penting dalam perjalanan secara kerajaan-kerajaan Islam di Nusantara. Hal ini terlihat dari semangat rajaraja untuk memperluas daerah kekuasaan dan meng-Islamkan para penduduk daerah kekuasaannya, keterlibatan para pemuka agama, hingga pengembangan kebudayaan yang bercorak Islam di Jawa. Pada awalnya daerah Mataram dikuasai kesultanan Pajang sebagai balas jasa atas perjuangan dalam mengalahkan Arya Penangsang. Sultan Hadiwijaya menghadiahkan daerah Mataram kepada Ki Ageng Pemanahan. Selanjutnya, oleh Ki Ageng Pemanahan Mataram dibangun sebagai tempat permukiman baru dan persawahan. Akan tetapi, kehadirannya di daerah ini dan usaha pembangunannya mendapat berbagai jenis tanggapan dari para penguasa setempat. Misalnya, Ki Ageng Giring yang berasal dari wangsa Kajoran secara terang-terangan menentang kehadirannya. Begitu pula Ki Ageng tembayat dan Ki Ageng Mangir. Namun masih ada yang menerima kehadirannya, misalnya Ki Ageng Karanglo. Meskipun demikian, tanggapan dan sambutan yang beraneka itu tidak mengubah pendirian Ki Ageng Pemanahan untuk melanjutkan pembangunan daerah itu. ia membangun pusat kekuatan di plered dan menyiapkan strategi untuk menundukkan para penguasa yang menentang kehadirannya.

Pada tahun 1575, Pemahanan meninggal dunia. Ia digantikan oleh putranya, Danang Sutawijaya atau Pangeran Ngabehi Loring Pasar. Di samping bertekad melanjutkan mimpi ayahandanya, ia pun bercita-cita membebaskan diri dari kekuasaan Pajang, sehingga hubungan antara Mataram dengan Pajang pun memburuk. Hubungan yang tegang antara Sutawijaya dan kesultanan Pajang 
akhirnya menimbulkan peperangan. Dalam peperangan ini, kesultanan Pajang mengalami kekalahan. Setelah penguasa pajak yakni Hadiwijaya meninggal dunia (1587), Sutawijaya mengangkat dirinya menjadi raja Mataram dengan gelar penembahan Senopati Ing Alaga. Ia mulai membangun kerajaannya dan memindahkan Senopati pusat pemerintahan ke Kotagede. Untuk memperluas daerah kekuasaanya, penembahan Senopati melancarkan serangan-serangan ke daerah sekitar. Misalnya dengan menaklukkan Ki Ageng Mangir dan Ki Ageng Giring.

Pada tahun 1590, penembahan Senopati atau biasa disebut dengan Senopati menguasai madiun, yang waktu itu bersekutu dengan Surabaya. Pada tahun 1591 ia mengalahkan Kediri, lalu melanjutkannya dengan penaklukkan Pasuruan dan Tuban pada tahun 1598-1599.

Sebagai raja Islam yang baru, panembahan Senopati melaksanakan penaklukan-penaklukan itu untuk mewujudkan gagasannya bahwa Mataram harus menjadi pusat budaya dan agama Islam, untuk menggantikan atau melanjutkan kesultanan Demak. Disebutkan pula dalam cerita babad bahwa cita-cita itu berasal dari wangsit yang diterimanya dari Lipura (desa yang terletak di sebelah barat daya Yogyakarta). Wangsit datang setelah mimpi dan pertemuan Senopati dengan penguasa laut selatan, Nyi Roro Kidul, ketika ia bersemedi di Parangtritis dan Gua Langse di Selatan Yogyakarta. Dari pertemuan itu disebutkan bahwa kelak ia akan menguasai seluruh tanah Jawa.

Sistem pemerintahan yang dianut kerajaan Mataram Islam adalah sistem Dewa-Raja. Artinya pusat kekuasaan tertinggi dan mutlak ada pada diri sultan. Seorang sultan atau raja sering digambarkan memiliki sifat keramat, yang kebijaksanaannya terpacar dari kejernihan air muka dan kewibawannya yang tiada tara. Raja menampakkan diri pada rakyat sekali seminggu di alun-alun istana. Selain sultan, pejabat penting lainnya adalah kaum priayi yang merupakan penghubung antara raja dan rakyat. Selain itu ada pula panglima perang yang bergelar Kusumadayu, serta perwira rendahan atau Yudanegara. Pejabat lainnya adalah Sasranegara, pejabat administrasi. Dengan sistem pemerintahan seperti itu, Panembahan Senopati terus-menerus memperkuat pengaruh Mataram dalam 
berbagai bidang sampai ia meninggal pada tahun 1601. ia digantikan oleh putranya, Mas Jolang atau Penembahan Seda Ing Krapyak (1601 -1613).

Peran Mas Jolang tidak banyak yang menarik untuk dicatat. Setelah Mas Jolang meninggal, ia digantikan oleh Mas Rangsang (1613-1645). Pada masa pemerintahannyalah Mataram mempunyai kejayaan. Baik dalam bidang perluasan daerah kekuasaan, maupun agama dan kebudayaan. Pangeran Jatmiko atau Mas Rangsang menjadi raja Mataram ketiga. Ia mendapat nama gelar Agung Hanyakrakusuma selama masa kekuasaan, Agung Hanyakrakusuma berhasil membawa Mataram ke puncak kejayaan dengan pusat pemerintahan di Yogyakarta.

Gelar "sultan" yang disandang oleh Sultan Agung menunjukkan bahwa ia mempunyai kelebihan dari raja-raja sebelumnya, yaitu panembahan Senopati dan Panembahan Seda Ing Krapyak. Ia dinobatkan sebagai raja pada tahun 1613 pada umur sekitar 20 tahun, dengan gelar "Panembahan". Pada tahun 1624, gelar "Panembahan" diganti menjadi "Susuhunan" atau "Sunan".

Pada tahun 1641, Agung Hanyakrakusuma menerima pengakuan dari Mekah sebagai sultan, kemudian mengambil gelar selengkapnya Sultan Agung Hanyakrakusuma Senopati Ing Alaga Ngabdurrahman. Karena cita-cita Sultan Agung untuk memerintah seluruh pulau Jawa, kerajaan Mataram pun terlibat dalam perang yang berkepanjangan baik dengan penguasa-penguasa daerah, maupun dengan kompeni VOC yang mengincar pulau Jawa. Pada tahun 1614, Sultan Agung mempersatukan Kediri, Pasuruan, Lumajang, dan Malang. Pada tahun 1615, kekuatan tentara Mataram lebih difokuskan ke daerah Wirasaba, tempat yang sangat strategis untuk menghadapi Jawa timur. Daerah ini pun berhasil ditaklukkan. pada tahun 1616, terjadi pertempuran antara tentara Mataram dan tentara Surabaya, Pasuruan, Tuban, Jepara, Wirasaba, Surabaya dan Sumenep. Peperangan ini dapat dimenangi oleh tentara Mataram, dan merupakan kunci kemenangan untuk masa selanjutnya. Di tahun yang sama Lasem menyerah. Tahun 1619, Tuban dan Pasuruan dapat dipersatukan. Selanjutnya Mataram berhadapan langsung dengan Surabaya. Untuk menghadapi Surabaya, Mataram melakukan strategi mengepung, yaitu lebih dahulu menggempur daerah-daerah 
pedalaman seperti Sukadana (1622) dan Madura (1624). Akhirnya, Surabaya dapat dikuasai pada tahun 1625. Dengan penaklukan-penaklukan tersebut, Mataram menjadi kerajaan yang sangat kuat secara militer. Pada tahun, 1627, seluruh pulau Jawa kecuali kesultanan Banten dan wilayah kekuasaan kompeni VOC di Batavia telah berhasil dipersatukan di bawah Mataram. Sukses besar tersebut menumbuhkan kepercayaan diri Sultan Agung untuk menantang kompeni yang masih bercongkol di Batavia. Maka, pada tahun 1628, Mataram mempersiapkan pasukan di bawah pimpinan Tumengggung Baureksa dan Tumenggung Sura Agul-agul, untuk menggempur Batavia. Sayang sekali, karena kuatnya pertahanan belanda, serangan ini gagal, bahkan tumengggung Baureksa gugur. Kegagalan tersebut menyebabkan matara bersemangat menyusun kekuatan yang lebih terlatih, dengan persiapan yang lebih matang. Maka pada pada 1629, pasukan Sultan Agung kembali menyerbu Batavia. Kali ini, Ki Ageng Juminah, Ki Ageng Purbaya, Ki Ageng Puger adalah para pimpinannya. Penyerbuan dilancarkan terhadap benteng Hollandia, Bommel, dan Weesp. Akan tetapi serangan ini kembali dapat dipatahkan, hingga menyebabkan pasukan Mataram ditarik mundur pada tahun itu juga. Selanjutnya, serangan Mataram diarahkan ke Blambangan yang dapat diintegrasikan pada tahun 1639.

Di luar peranan politik dan militer, Sultan Agung dikenal sebagai penguasa yang besar perhatiannya terhadap perkembangan Islam di tanah Jawa. Ia adalah pemimpin yang taat beragama, sehingga banyak memperoleh simpati dari kalangan ulama. Secara teratur, ia pergi ke masjid, dan para pembesar diharuskan mengikutinya. Untuk memperkuat suasana keagamaan, tradisi khitan, memendekkan rambut bagi pria, dan mengenakan tutup kepala berwarna putih, dinyatakan sebagai syariat yang harus ditaati.

Bagi Sultan Agung, kerajaan Mataram adalah kerajaan Islam yang mengemban amanat Tuhan di tanah Jawa. Oleh sebab itu, struktur serta jabatan kepenghuluan dibangun dalam sistem kekuasaan kerajaan. Tradisi kekuasaan seperti sholat jumat di masjid, grebeg ramadan, dan upaya pengamalan syariat Islam merupakan bagian tak terpisahkan dari tatanan istana. 
Sultan Agung juga berprediksi sebagai pujangga. Karyanya yang terkenal yaitu Kitab Serat Sastra Gendhing. Adapun Kitab Serat Nitipraja digubahnya pada tahun 1641. Serat Sastra Gendhing berisi tetang budi pekerti luhur dan keselarasan lahir batin. Serat Nitipraja berisi tata aturan moral, agar tatanan masyarakat dan negara dapat menjadi harmonis. Selain menulis, Sultan Agung juga memerintahkan para pujangga Keraton untuk menulis sejarah babad tanah jawi. Di antara semua karyanya, peran Sultan Agung yang lebih membawa pengaruh luas adalah dalam penanggalan. Sultan Agung memadukan tradisi pesantren Islam dengan tradisi kejawen dalam perhitungan tahun. Masyarakat pesantren biasa menggunakan tahun hijriah, masyarakat kejawen menggunakan tahun caka atau saka. Pada tahun 1633, Sultan Agung berhasil menyusun dan mengumumkan berlakunya sistem perhitungan tahun yang baru bagi seluruh Mataram. Perhitungan itu hampir seluruhnya disesuaikan dengan tahun hijriah, berdasarkan perhitungan bulan. Namun, awal perhitungan tahun Jawa ini tetap sama dengan tahun saka, yaitu $78 \mathrm{M}$. Kesatuan perhitungan tahun sangat penting bagi penulisan serat babad. Perubahan perhitungan itu merupakan sumbangan yang sangat penting bagi perkembangan proses peng-Islaman tradisi dan kebudayaan Jawa yang sudah terjadi sejak berdirinya kerajaan Demak. Hingga saat ini, sistem penanggalan ala Sultan Agung ini masih banyak digunakan.

Sejak masa sebelum Sultan Agung pembangunan non-militer memang telah dilakukan. Satu yang layak disebut, panembahan Senopati menyempurnakan bentuk wayang dengan tatanan gempuran. Setelah zaman Senopati, Mas Jolang juga berjasa dalam kebudayaan, dengan berusaha menyusun sejarah negeri Demak, serta menulis beberapa Kitab Suluk. Misalnya Suluk Wujil (1607) yang berisi wejangan Sunan Bonang kepada abdi raja Majapahit yang bernama Wujil. Pangeran Karanggayam juga menggubah Serat Nitisruti (1612 ) pada masa Mas Jolang.

Menjelang akhir hayatnya. Sultan Agung menerapkan peraturan yang bertujuan mencegah perebutan tahta, antara keluarga raja dan putra mahkota. Di bawah kepemimpinan Sultan Agung, Mataram tidak hanya menjadi pusat kekuasaan, tapi juga menjadi pusat penyebaran Islam. Sultan Agung meninggal 
pada Februari 1646. ia dimakamkan di puncak Bukit Imogiri, Bantul,Yogyakarta. Selanjutnya, Mataram diperintah oleh putranya, Sunan Tegalwangi, dengan gelar Amangkurat I ( 1646 - 1677). Dalam masa pemerintahan Amangkurat I, kerajaan Mataram mulai mundur. Wilayah kekuasaan Mataram berangsur-angusr menyempit karena direbut oleh kompeni VOC. Yang paling mengenaskan, pada tahun 1675, Raden Trunajaya dari Madura memberontak. Pemberontakannya demikian tak terbendung, sampai-sampai Trunajaya berhasil menguasai keraton Mataram yang waktu itu teletak di Plered. Amangkurat terlunta-lunta mengungsi, dan akhirnya meninggal di Tegal. Sepeninggal Amangkurat I, Mataram dipegang oleh Amangkurat II yang menurunkan Dinasti Paku Buwana di Solo dan Hamengku Buwana di Yogyakarta. Amangkurat II meminta bantuan VOC untuk memadamkan pemberontakan Trunajaya. Setelah berakhirnya Perang Giyanti (1755), wilayah kekuasaan Mataram semakin terpecah belah. Berdasarkan perjanjian Giyanti, Mataram dipecah menjadi dua, yakni Mataram Surakarta dan Mataram Yogyakarta. Pada tahun 1757 dan 1813, perpecahan terjadi lagi dengan munculnya Mangkunegara dan Pakualaman. Di masa pemerintahan Hindia Belanda, keempat pecahan kerajaan Mataram ini disebut sebagai vorstenlanden. Saat ini, keempat pecahan Kesultanan Mataram tersebut masih melanjutkan dinasti masing-masing. Bahkan peran dan pengaruh pecahan Mataram tersebut, terutama kesultanan Yogyakarta masih cukup besar dan diakui masyarakat.

\section{Islam dan Budaya Mayarakat Yogyakarta}

Masyarakat adalah orang yang hidup bersama yang menghasilkan kebudayaan. Dengan demikian tidak ada masyarakat yang tidak mempunyai kebudayaan dan sebaliknya tidak ada kebudayaan tanpa masyarakat sebagai wadah dan pendukungnya. Dua orang Antropolog terkemuka yaitu Melville J. Herskovits dan Bronislaw MalinowsKi mengemukakan bahwa Cultural Determinism berarti segala sesuatu yang terdapat di dalam masyarakat ditentukan adanya oleh kebudayaannya yang dimiliki oleh masyarakat itu (Soemardjan, dkk.,1964: 115) 
Kajian Budaya (Cultural Studies) menyajikan bentuk kritis atas definisi budaya yang mengarah pada "the complex everyday world we all encounter and through which all move" (Edgar, 1999: 102). Budaya secara luas adalah proses kehidupan sehari-hari manusia dalam skala umum, mulai dari tindakan hingga cara berpikir, sebagaimana konsep budaya yang dijabarkan oleh Kluckhohn. Budaya masyarakat Yogjakarta, jika menurut teori tersebut, tentunya Islam yang membawa nilai-nilai dalam bentuk aturan dalam kehidupan sehari-hari telah secara tidak langsung mempengaruhi proses kehidupan sehari-hari masyarakat dan tentunya juga pada tindakan cara berpikir, sehingga banyak kegiatan-kegiatan yang dilakukan bernafaskan Islami.

Untuk kepentingan analisis dalam penulisan ini, maka dari sudut struktur dan tingkatan dikenal adanya culture dan sub culture. Di dalam suatu culture yang mungkin berkembang lagi kebudayaan-kebudayaan khusus yang tidak bertentangan dengan kebudayaan 'induk', maka disebut sub culture (Soekamto, 2002:174)

Islam masuk tanah Jawa melalui socio culture. Pelaksanaan syariat Islam agar dapat mudah diterima, maka yang dapat dilakukan adalah melalui penyesuaian dengan budaya masyarakat Jawa. Islam dengan nilai-nilainya yang tidak bertentangan dengan budaya masyarakat Jawa (culture) merupakan sub culture yang selanjutnya dengan mudahnya Islam dapat diterima dengan baik oleh masyarakat. Seperti diceritakan di dalam naskah keraton (antara lain: Serat Cebolek dan Babad Giyanti) menceritakan, bahwa Pangeran Mangkubumi (Pendiri Keraton Yogya), Putra Amangkurat IV adalah seorang pejuang yang taat beragama. Dikisahkan, Sholat lima waktunya tidak pernah ditinggalkan, gemar mengaji bahkan hafal sebagian ayat-ayat Al-Qur'an, dan melakukan Puasa Senin dan Kamis, peduli pada fakir miskin, kaum yang lemah dipedesaan (Serat Cebolek).

Ketika Perang melawan Penjajah Belanda, Pangeran Mangkubumi selalu membuat Musholla, di pos-pos pasukannya di pedesaan. Musholla itu difungsikan untuk jama'ah Sholat fardlu, juga untuk mensholatkan para Syuhada yang gugur dalam perjuangan (Babad Giyanti). Setelah Perjanjian Giyanti, Panembahan 
Senopati, dinobatkan menjadi Sri Sultan Hamengkubuwono I, dengan gelar," Sri Sultan Hamengkubuwana Senopati Ing Ngalaga Ngabdurrahman Sayidin Panatagama Kalifatullah Ing Ngayogyakarta”.

Kesenjangan melalui penyimpangan budaya Jawa sebagai budaya induk, akan mempersulit Islam dapat diterima di tanah Jawa.Oleh sebab itu pelaksanaan syariat dan nilai-nilai Islam juga harus dikemas dalam budaya masyarakat Jawa. Dengan demikian ada banyak budaya Jawa yang kemudian terbentuk dengan nuansa Islami.

Berikut ini beberapa budaya Jawa khususnya di Yogjakarta yang bernafaskan Islam( Nana Sudiana, http://sejarah.kompasiana):

\section{Kegiatan Sosial}

Keraton Yogya juga menghidupkan Tuntunan Islam (Syari'at), yaitu antara lain menjalankan hukum Islam dengan membuat "Mahkamah Al Kaburoh" di Serambi Masjid Gede Kauman, membuat Masjid Kerajaan (Masjid Gedhe), juga membuat Masjid Pathok Negara (Batas negara Agung/IbuKota), dilengkapi tanah perdikan (mirip Tanah Wakaf) untuk pesantren. Dibangun pula Masjid Panepen (Untuk nenepi/I'tikaf) Sultan, letaknya didalam Keraton. Dan Masjid Suronoto untuk Sholat para abdi dalem (letaknya di Keben). Selain Masjid, dalam struktur Keraton juga terdapat pejabat yang mengurusi perkembangan agama Islam, yang dikepalai oleh penghulu keraton, dibantu Kaji Selusinan, dan para Ketib.

Keraton Yogya juga menghidupkan upacara-upacara budaya yang bernafaskan Islam, yang dirintis sejak Zaman Kerajaan Demak dan Mataram Islam. Seperti: Sekaten, Grebeg Mulud (untuk memperingati Maulid Nabi Muhamad SAW); Grebeg Syawal dan Silahturahmi Sultan dengan Rakyat ( Untuk menyambut Idul Fitri); Grebeg Besar (memperingati Hari Raya Idul Adha); tidak lupa Sultan membagikan Zakat Fitrah dan Hewan Qurban.

Keturunan Sultan, yaitu Sentana Dalem bila akan menikah harus dengan sesama Muslim. Pernikahan dan pembagian waris di Keraton juga menggunakan 
hukum Islam. Di dalam lingkungan benteng Keraton (njeron benteng) tidak boleh ada warga asing China, dan tidak diperbolehkan berdiri tempat Ibadah kecuali hanya Masjid.

Pada awalnya, setiap Jum'at Kliwon, Sultan khutbah di Masjid Gedhe, dan juga tidak dilarang ibadah Haji. Namun setelah adanya Java Oorlog (Perang Jawa/Perang Diponogoro), maka Penjajah Belanda membuat peraturan ketat kepada Sultan Yogyakarta yang dinilai patriotik melawan Belanda dan membantu Pangeran Diponogoro dari belakang.

Pihak Belanda mencurigai bahwa semangat patriotik melawan penjajah belanda itu ada pengaruh dari Ibadah Haji bagi Sultan Yogya. Sejak itu, Sultan Yogya dilarang beribadah Haji. Selain itu, Sultan juga dibatasi untuk Sholat di Masjid Gedhe, tidak boleh Khutbah, dalam rangka memisahkan silahturahmi dan kharisma denga rakyatnya. Terhadap karyatulis resmi kerajaan, mendapatkan sensor ketat, sehingga mematikan kreativitas para pujangga keraton. Dan yang paling membelenggu Sultan ialah untuk pemerintahan harian harus didelegasikan kepada Patih (yang digaji dan mendapat pengaruh Penjajah Belanda).

Sejak itu, terutama dimasa Sultan HB V sampai HB VII, posisi Sultan lemah. Penjajah Belanda mulai memasukkan pengaruhnya ke dalam Keraton, melalui pendidikan, seperti Sekolah Taman (yang gurunya orang-orang Belanda); memasukkan para suster rumah saKit Belanda untuk merawat keluarga Sultan. Pihak penjajah Belanda juga meminta tanah milik Keraton di luar benteng untuk didirikan antara lain Rumah Sakit, Biara, Gereja, dan Sekolah-sekolah Nasrani di Yogyakarta. Oleh karena itu, kegiatan budaya Keraton dan agama Islam, agak kurang terang-terangan, sehingga lebih banyak dimunculkan dengan simbolsimbol yang dibungkus dengan budaya Jawa.

\section{Seni dan Sastra}

Budaya berwujud seni yang bernafaskan agama di Yogyakarta, dapat dilihat antara lain pada: Seni Sastra, seperti serat Muhammad, Serat Ambiya', Serat Tajus Salatin, dan sebagainya. Seni suara, seperti Macapat, Langen Swara, Salawatan. Seni lukis, seperti kaligrafi di bangunan Keraton dan Masjid. Seni 
musik seperti Gamelan Sekaten. Seni Pedalangan, seperti dimunculkannya wayang sadat, episode Dewa Ruci dan Jimat kalimasada, serta tokoh punokawan dalam pewayangan, dan sebagainya.

Pelajaran sejarah dari berbagi peradaban dunia mengajarkan, bahwa hanya dengan sikap konsisten atas nilai-nilai-lah yang menyebabkan sebuah peradaban dapat tumbuh kembali, setelah masa suramnya. Dan nilai-nilai itu, bisa ditelusuri dari masa pembentukan peradaban itu (the formative age). Seperti: Masa renaissance dan industrialisasi Eropa yang menumbuhkan kembali Etika Protestan; Peradaban Islam, yang bersumber dari ajaran dan teladan Nabi Muhammad SAW; Kebangkitan Asia Timur dewasa ini yang menghidupkan kembali nilai "Confusianisme"; dan Bangsa Jepang dengan shintoisme dan etika Bushido-nya.

Sebaliknya, masa suram sebuah Kerajaan, biasanya karena faktor luar dan dalam. Faktor luar adalah penjajahan, faktor dalam yakni, lunturnya nilai-nilai perjuangan dan akhlaq para Elite Kerajaan (Keluarga; Kesatria; Ulama), sehingga Kerajaan itu mudah dikendalikan Bangsa lain. Hikmah Kenabian mengajarkan, bahwa kekuasaan itu memang digilirkan antar Bangsa (dikenal sebagai prinsip "Mudawalah"). Hanya dengan kepemimpinan yang berorientasi menjadi teladan dan melayani rakyatnya (Prinsip Pamong), suatu Bangsa akan menjadi besar.

Pelajaran sejarah dari masa pembentukan Keraton Yogyakarta adalah bahwa antara rakyat dan Raja telah memiliKi tradisi "menyatu" sejak zaman perjuangan Panembahan Senopati. Dan hal ini terjadi lagi khususnya di masa perjuangan merebut kemerdekaan dimasa Sultan HB IX. DemiKian juga, antara budaya dan agama Islam telah senafas, dengan penonjolan pada simbol budaya Jawa.

\section{Prinsip Hidup}

Dalam memahani budaya Yogyakarta, dapat di mulai dari mengerti kaedah kehidupan dasar dalam kehidupan masyarakat Yogyakarta, yaitu: Pertama: Prinsip RUKUN, yaitu untuk mewujudkan dan mempertahankan masyarakat dalam keadaan yang harmonis (tenang, selaras, tentram, bersatu saling membantu). Kedua: Prinsip HORMAT, yaitu memainkan peran yang besar dalam mengatur pola interaksi social masyarakat Jawa . Rasa saling menghormati ini memiliKi 
peran yang besar dalam masyarakat Yogyakarta (baca: Clifford Geetz: The Religion Of Java).

Selain dua kaedah dasar diatas, masyarakat Yogyakarta memiliKi beberapa nilai yang menjadi pegangan dalam kehidupannya. Telah banyak studi untuk merumuskan nilai-nilai budaya Yogyakarta. Sebagai contoh, ditulis sebagai berikut :

NRIMO : Mensyukuri kepada apa yang telah diperoleh, dan jika terjadi sesuatu halangan setelah diusahakan, maka mereka nrimo atau pasrah kepada Allah, menyadari bahwa itu sudah menjadi kehendaknya (nrimo ing pandum). (Dalam ajaran Islam, sikap mensyukuri karunia Allah SWT, merupakan kewajiban bagi seorang Hamba, dan Allah SWT akan memberikan berkah karunia yang lebih banyak dimasa mendatang).

SABAR : "Sing Sabar Subur", artinya orang yang sabar itu akan mendapatkan kesejahteraan dan keselamatan. Dalam menyelesaikan masalah tidak boleh gegabah, dalam mengusahakan sesuatu tidak "nggege mangsa", menurut prosedur yang benar, dilakukan dengan penuh kesabaran.

GOTONG ROYONG : Adalah nilai kebersamaan yang saling peduli, saling membantu meringankan beban dalam kehidupan bermasyarakat. Ajaran Gotong royong ini, dapat ditelusuri dari ajaran Islam, yang menganjurkan,’Bertolongtolonglah kamu dalam perbuatan baik berdasarkan Taqwa”.

TAKWA : Dalam masyarakat Jawa, Taqwa merupakan pakaian dalam kehidupan, yaitu diajarkan dekat dengan Allah SWT. Dengan mentaati perintah dan laranganNya. Takwa ini disimbolkan dengan "baju Takwo".

REMBUG BARENG : Didalam memutuskan sesuatu yang mengandung harkat, kepentingan orang banyak. Maka selalu diadakan rembug bareng, sering juga disebut rembug deso. Hal ini sinonim dengan ajaran Islam, yang diadopsi bangsa Indonesia, yakni: Musyawarah.

TEPA-SLIRA : Adalah memahami dan menghormati perasaan orang lain, dalam rangka menjaga persaudaraan, dan menjauhkan dari segala macam konflik. Tepaslira dalam ajaran Islam, dikenal denga istilah Tafahum (saling memahami dalam perbedaan); atau dalam bahasa Indonesia disebut "toleran". 
OJO DUMEH : Dilarang berbuat Kibir (takabur atau sombong), dan merendahkan orang lain.

Dalam budaya politik, ada beberapa segi budaya politik Yogyakarta yang bisa dikembangkan sebagai "khasanah budaya demokrasi Yogyakarta". Seperti : pejabat negara mendapatkan status sebagai "Pamong" sama dengan "Pangon" yang artinya penggembala. Makna yang terkandung didalamnya ialah pejabat negara adalah pelayan Ummat, yang melindungi, mengusahakan kesejahteraan bagi masyarakatnya. Oleh karena itu zaman dulu, tidak menggunakan kata "Pemerintah" (yang berkonotasi tukang Perintah). Sesungguhnya istilah "Pamong" lebih tepat untuk budaya Yogyakarta (sinonim dengan kata RO'IN, yang berarti penggembala atau mengelola).

Demikian beberapa sifat budaya masyarakat Yogyakarta, yang telah mengakar, dan senafas dengan ajaran keagamaan. Dengan nilai-nilai Agama Islam, sebagai “dasar nilai” budaya masyarakat Yogyakarta. Tentu saja diperlukan kajian lebih lanjut untuk merumuskan nilai dan budaya masyarakat Yogyakarta yang dinamis, secara komprehensif.

Menurut GBPH Joyokusumo, dikutip oleh A.Adaby Darban (2002), Nilai dasar atau ruh Keraton Yogya adalah ajaran Islam. Oleh karena itu, kunci untuk mengungkap Keraton Yogya adalah dengan ajaran Islam. Ajaran yang berupa Hakekat, Syari'at, dan Ma'rifah Islamiyah diusahakan berjalan dengan menggunakan simbol-simbol dan pendekatan budaya Jawa. Karena itu untuk meneguhkan jatidiri budaya masyarakat Yogyakarta, perlu kembali kepada nilainilai dasar (ajaran Islam) budaya masyarakat Yogyakarta.

\section{Simpulan}

Kehidupan Keraton Yogyakarta yang bernuansa Islami adalah pengaruh dari kerajaan Islam Mataram. Islam sebagai agama yang berasal dari timur tengah telah dapat diterima masyarakat Jawa, khususnya masyarakat Yogyakarta, karena sebagai sub culture, Islam tidak bertentangan dengan budaya induk Jawa, dan banyak nilai-nilai di dalam agama Islam yang sesuai dengan nilai-nilai kehidupan 
masyarakat Jawa. Dengan demikian Islam mudah diterima dengan baik di tanah Jawa dan menyatu dalam kebudayaan masyarakat Yogyakarta. Islam yang membawa nilai-nilai dalam bentuk aturan dalam kehidupan sehari-hari telah secara tidak langsung mempengaruhi proses kehidupan sehari-hari masyarakat dan tentunya juga pada tindakan cara berpikir, sehingga banyak kegiatan-kegiatan yang dilakukan bernafaskan Islami.

\section{Daftar Pustaka}

Barker, Chris,2005. Cultural Studies : Teori dan Praktik, Terj. Tim KUNCI Cultural Studies Centre, Bentang

Edgar, Andrew and Peter Sedgwick (ed.), 1999. Cultural Theory The Key Concepts, Routledge

Hariwijaya, M.2007. Kerajaan-Kerajaan Islam di Nusantara. Pustaka Insan Madani. Yogjakarta

Koentjaraningrat, 1990.Pengantar Ilmu Antropologi, Rineka Cipta

Nana Sudiana, 4 April 2011.Sisi Islami Keraton Yogjakarta, http://sejarah .kompasiana.com

Soekamto, Soerjono.2002. Sosiologi Suatu Pengantar. Raja Grafindo. Jakarta

Selo Soemardjan, dkk.,1964.Setangkai Bunga Sosiologi.Yayasan Badan Penerbit FE UI 